\title{
RANCANG BANGUN APLIKASI WEB MOBILE MANAJEMEN TERNAK JANGKRIK DI UMKM BOS JANGKRIK JOGJA
}

\author{
Aswindra Aji Kurniawan \\ Teknik Informatika, Teknologi Industri \\ Universitas Ahmad Dahlan \\ aswinwonolagi@gmail.com
}

\begin{abstract}
ABSTRAK
Ternak Jangkrik merupakan jenis usaha yang jika tidak direncanakan dengan matang, akan sangat merugikan usaha. Ada beberapa tahap yang perlu diperhatikan dalam merencanakan usaha ternak jangkrik, yaitu penyusunan jadwal kegiatan, menetapkan fasilitas fisik, dan menentukan spesifikasi pekerjaan. Dalam hal ini yang paling penting adalah penjadwalan kegiatan, karena dalam proses ternak jangkrik memerlukan banyak proses dalam pemeliharaannya yaitu proses penetasan, pemberian pakan, dan jadwal panen. Dalam hal ini, pendampingan ternak jangkrik oleh Petugas Pendamping Ternak sangat penting untuk membantu peternak dalam melakukan proses kegiatan ternak. Di UMKM Bos Jangkrik Jogja, para peternak yang tergabung dalam anggota ternak banyak berdomisili di luar wilayah Gunungkidul sehingga Petugas Pendamping Ternak (PPT) merasa kesulitan dalam melakukan proses pendampingan ternak. Saat ini proses pendampingan ternak masih dilakukan dengan cara datang langsung ke lokasi peternakan. Masalah tersebut dapat diatasi dengan Aplikasi Mobile dan Aplikasi Web yang sedang dikembangkan. Agar penyampaian informasi mengenai jadwal kegiatan ternak dapat dilakukan dengan mudah maka dibutuhkan Web Service yang mampu mengirim jadwal kegiatan ternak secara otomatis berupa Push Notification yang dikirim ke Aplikasi Mobile.

Metodologi yang digunakan dalam penelitian ini yaitu melakukan pengumpulan data menggunakan metode wawancara dan observasi. Kemudian dianalisis untuk menentukan kebutuhan user dan kebutuhan sistem. Implementasi aplikasi memanfaatkan codeigniter framework dan Java Android. Pengujian sistem dilakukan dengan metode Blackbox Test.
\end{abstract}

Kata Kunci: Manajemen Ternak, Aplikasi Mobile, Web Service, Push Notification, Android Cloud To DeviceMessaging.

\begin{abstract}
Livestock Cricket is a type of business that, if not carefully planned, would be detrimental to the business. There are several steps that need to be considered in planning the cattle business crickets, namely the preparation of activity schedules, assign physical facilities, and determine the specifications of the job. In this case the most important is the scheduling of activities, because in the process of livestock crickets require much maintenance processes in which the process of hatching, feeding and harvesting schedules. In this case, livestock assistance crickets Officer Companion Animal very important to help farmers in the process of livestock activities. Crickets in the SME boss Jogja, farmers who are members of many animal members domiciled outside the Gunung so Officer Companion Animal (PPT) had difficulty in doing mentoring process cattle. Currently the livestock mentoring process is still done by coming directly to the location of the farm. The problem can be solved by a Mobile and Web applications that are being developed. In order to deliver information about the schedule of livestock can be easily then the required Web Service which can send automatically schedule livestock activities such as Push Notification is sent to the Mobile Application. The methodology used in this study is collecting data using interviews and observation. Then analyzed to determine user needs and system requirements. Implementation of applications utilizing CodeIgniter framework and Java Android. Testing of the system was conducted by Blackbox Test.
\end{abstract}

Key words: Livestock Management, Mobile Applications, Web Services, Push Notification, Android Cloud To DeviceMessaging. 


\section{PENDAHULUAN}

\subsection{Latar Belakang Masalah}

Ternak Jangkrik merupakan jenis usaha yang jika tidak direncanakan dengan matang, akan sangat merugikan usaha. Ada beberapa tahap yang perlu diperhatikan dalam merencanakan usaha ternak jangkrik, yaitu penyusunan jadwal kegiatan, menetapkan fasilitas fisik, dan menentukan spesifikasi pekerjaan [1]. Dalam hal ini yang paling penting adalah penjadwalan kegiatan, karena dalam proses ternak jangkrik memerlukan banyak proses dalam pemeliharaannya yaitu proses penetasan, pemberian pakan, dan jadwal panen. Dalam hal ini, pendampingan ternak jangkrik oleh Petugas Pendamping Ternak sangat penting untuk membantu peternak dalam melakukan proses kegiatan ternak.

Berdasarkan data yang diperoleh dari hasil wawancara dengan Kepala UMKM Bos Jangkrik Jogja, Ahmad Nur Shoim, Petugas Pendampingan Ternak saat ini merasa kesulitan mendampingi para peternak agar hasil panen bisa maksimal dan memenuhi target, terutama pendampingan untuk peternak yang berada di luar wilayah Yogyakarta. Hal ini desebabkan karena jauhnya lokasi peternak. Saat ini proses pendampingan ternak yang dilakukan oleh Petugas Pendampingan Ternak (PPT) adalah dengan cara datang langsung ke lokasi ternak, tetapi dengan cara seperti itu menghabiskan banyak biaya, waktu, dan tenaga. Pada saat Petugas Pendampingan Ternak (PPT) datang ke lokasi ternak sering kali peternak yang didatangi tidak ada di lokasi karena kurang sinkronnya waktu yang dimiliki oleh peternak karena masing-masing peternak memiliki pekerjaan, sehingga proses pendampingan kurang terlaksana dengaan baik. UMKM Bos Jangkrik Jogja menginginkan sebuah Aplikasi berbasis Mobile Smartphone agar proses penyebaran Informasi dari Petugas Pendamping Ternak (PPT) kepada peternak lebih cepatdan tepat tanpa harus datang ke lokasi peternakan, karena saat ini para peternak dan Petugas Pendampingan Ternak (PPT) sudah memiliki Smartphone.

Keberadaan teknologi Internet dan Aplikasi Mobile saat ini sebenarnya bisa dimanfaatkan secara optimal sebagai salah satu media penyebaran Informasi. Sepanjang 2013 hingga 2017, penetrasi mobile phone akan tumbuh dari 61,1 persen menjadi 69,4 persen secara global. eMarkerter memprediksi, makin semaraknya smartphone murah dengan dukungan konektivitas $3 \mathrm{G}$ dan 4G akan mendorong konsumen beralih ke smartphone [2]. Statistik perkembangan internet di Indonesia mencapai $15 \%$ atau $38,191,873$ pengguna internet dari total populasi kita $251,160,124$, Sedang pengguna internet dengan menggunakan mobile/smartphone mencapai $14 \%$ dari populasi [3]. Sehingga pada saat ini Perangkat Mobile merupakan Hardware yang paling efisien sebagai media penyebaran Informasi.

Google Cloud Messaging (GCM) merupakan system push notification service yang berdasarkan dari C2DM (Cloud to Device Messeging) dengan beberapa perkembangan seperti mendukung multicast messages, tidak tegantung dengan kuota, mendukung JSON notification messages, mempunyai daya tahan baterai handphone lebih. Namun demikian, desain fundamental dari botnet C2DM memanfaatkan layanan push notification sebagai C \& C channel, dan mungkin botnet GCM lebih efektif dalam penyebaran notifikasi karena dapat dikirim lewat multicast, dan tidak memakai kuota. Dengan mengusung teknologi tersebut Petugas Pendampingan Ternak (PPT) tidak harus setiap waktu mengingatkan para peternak mengenai proses peternakan. Proses pendampingan cukup dilakukan dalam satu kali proses penjadwalan dan para peternak akan menerima pemberitahuan otomatis dan realtime pada Mobile Smartphone Android mereka. Dengan cara ini proses pendampingan ternak oleh Petugas Pendampingan Ternak dan proses pengontrolan ternak oleh peternak akan lebih mudah.

\section{LANDASAN TEORI}

\subsection{Jangkrik}

Menurut Soenanto (1999), Jangkrik adalah serangga (insecta) dengan subkelas Pterygota, berukuran sedang dengan panjang kurang lebih $3 \mathrm{~cm}$. Dalam kehidupan aslinya, habitat jangkrik hidup di alam bebas seperti sawah, ladang, dan kebun. Konsumsi makanannya yaitu daun-daunan serta biji-bijian yang 
ditemukan di tempat keberadaannya [10]. Jangkrik memiliki banyak manfaat antara lain:
A. Sebagai Nyamikan
B. Pakan Burung dan Ikan
C. Sebagai campuran kosmetik

Seiring dengan berjalannya waktu, beternak jangkrik ternyata memiliki prospek yang cerah dan dapat mendatangkan keuntungan yang luar biasa. Maraknya peminat burung kicauan dan tingginya permintaan para pemelihara ikan menyebabkan semakin tingginya jumlah kebutuhan jangkrik. Hal ini mendorong orang untuk mengembangbiakkan jangkrik.

Pada proses penetasan, dari telur-telur yang tersimpan dalam mesin penetas akan menetas dalam waktu 4 sampai 7 hari. Setelah menetas yang dilakukan adalah memberikan pakan berupa sayuran, misalnya labu siam dan sawi putih. Tetapi sebelum ditaburkan di sekeliling kotak terlebih dahulu sayuran harus dianginanginkan minimal 6 jam.

Pada proses pemberian pakan, jenis pakan jangkrik tidak sekedar asal tetapi memiliki jenis sayuran yang disesuaikan dengan umur jangkrik.

\subsection{Android Cloud to Device Mesaging}

Android Cloud to Device Messaging (AC2DM) merupakan sebuah layanan (service) yang membantu para pengembang software untuk dapat mengirimkan data dari server ke aplikasi yang sudah terpasang di piranti mobile berbasis Android. Layanan ini menyediakan sebuah mekanisme yang sederhana, ringan dan cepat untuk membantu server agar dapat digunakan untuk mengirimkan pesan atau data ke aplikasi yang telah terpasang di piranti mobile secara langsung, sehingga user dapat menerima informasi terbaru dengan cepat saat itu juga [4]. Layanan AC2DM menangani seluruh aspek mulai dari pengiriman pesan dari server aplikasi hingga masuk ke frontend C2D (cloud to device), connectionserver, hingga pengiriman notifikasi ke aplikasi sasaran di piranti mobile Android.

\subsection{Web Service}

Menurut Stephen Potts (2003), Webservice adalah aplikasi yang diakses melalui internet menggunakan protokol standar internet dan menggunakan XML sebagai format pesannya
[6]. Web service memiliki tiga entitas dalam arsitekturnya, yaitu:

i. $\quad$ Service Requester (peminta layanan)

ii. Service Provider (penyedia layanan)

iii. Service Registry (daftar layanan)

\section{METODE PENELITIAN}

\subsection{Objek Penelitian}

Objek penelitian yang akan dibahas pada tugas akhir ini adalah manajemen ternak yang dilakukan oleh Petugas Pendampingan Ternak dan komunikasi serta pemantauan secara otomatis melalui aplikasi web mobile mengenai proses berternak Jangkrik. Alasan untuk memilih UMKM Bos Jangkrik Jogja sebagai objek penelitian adalah perlunya sebuah Aplikasi berbasis Mobile Smartphone agar proses penyebaran Informasi dari Petugas Pendamping Ternak (PPT) kepada peternak lebih cepat dan tepat tanpa harus datang ke lokasi peternakan. Aplikasi Mobile ini diharapkan peternak dapat menerima Informasi dari Petugas Pendampingan Ternak secara realtime dan Petugas Pendampingan Ternak lebih mudah dan cepat dalam melakukan proses pendampingan ternak.

\subsection{Metode Pengumpulan Data}

Metode pengumpulan data yang dilakukan dalam penelitian ini adalah sebagai berikut :

\section{a. Observasi}

Metode observasi dilakukan dengan cara melakukan pengamatan secara langsung di Kantor Manajemen UMKM Bos jangkrik Jogja dan dilanjutkan dengan pengamatan secara cermat dan sistematis sesuai dengan kondisi yang sebenarnya. Seperti pengamatan pada proses pendampingan ternak yang dilakukan oleh Petugas Pendampingan Ternak (PPT) di lokasi peternakan.

\section{b. Wawancara}

Metode wawancara dilakukan dengan mengadakan tanya jawab kepada Kepala UMKM Bos Jangkrik Jogja yaitu Ahmad Nur Shoim, SE., mengenai permasalahan yang ada pada saat proses pendampingan ternak terutama untuk pendampingan ternak kepada 
peternak yang berada di luar wilayah Yogyakarta.

\subsection{Alat Penelitian}

a. Perangkat Keras (Hardware)

1. Laptop

2. ProcessorIntelCeleron $2.00 \mathrm{GHz}$

3. RAM 2 GB

4. Hardisk $500 \mathrm{~GB}$

5. SmartphoneAndroid

b. Perangkat Lunak (Software)

1. Sistem Operasi: Windows 7, OS Android

2. Bahasa Pemrograman: Java, Android, PHP, HTML dan CSS.

3. Tools: Eclipse, Android Virtual Device, Codeigniter, Sublime, Corel Draw, Photoshop.

\subsection{Analisis Kebutuhan}

Kegiatan dalam tahap ini adalah menganalisis kebutuhan untuk membangun Aplikasi pendampingan ternak jangkrik untuk petugas dan peternak di UMKM Bos Jangkrik Jogja. Kegiatan analisis sistem yang dilakukan mencakup kebutuhan fungsional, kebutuhan non-fungsional, dan usecase diagram. Hasil dari analisis kebutuhan sistem ini dijadikan sebagai dasar untuk menentukan spesifikasi sistem pencarian yang akan dikembangkan adalah sebagai berikut :

\section{Kebutuhan Fungsional}

Kebutuhan fungsional adalah kebutuhan untuk system menggambarkan apa yang sistem yang harus lakukan [11]. Aplikasi yang akan dibangun ini memiliki beberapa fungsionalitas antara lain membantu pengelolaan data peternak, data penetasan, dan data jual beli sehingga proses pengelolaan data yang dilakukan oleh Petugas akan lebih mudah.

\section{Kebutuhan Non-Fungsional}

Kebutuhan non fungsional adalah Kebutuhan yang tidak langsung berkaitan dengan fungsi-fungsi khusus yang disampaikan oleh sistem [11]. Pembuatan Aplikasi Mobile pendampingan ternak menghasilkan media informasi jadwal kegiatan ternak yang di kirim ke perangkat mobile peternak.

\section{Use Case Diagram}

Kegiatan yang dilakukan pada tahap ini adalah merancang sistem menggunakan UML dan merancang antarmuka (userinterface).

a. Perancangan sistem menggunakan use case diagram untuk menggambarkan kebutuhan user dan administrator. Untuk menggambarkan relasi antar object dan class di dalam sistem tersebut menggunakan class diagram.

b. Perancangan antarmuka meliputi struktur menu, input dan output pada halaman-halaman untuk bagian user dan administrator agar nyaman digunakan.

\subsection{Perancangan Sistem}

\section{Perancangan Basis Data}

Perancangan basis data digunakan untuk menggambarkan model data yang ada pada sistem yang akan dikembangkan dan untuk menggambarkannya digunakan classdiagram yang bertujuan untuk menggambarkan relasi antar objek dan class yang ada dalam sistem.

\section{Perancangan Antarmuka}

Perancangan antarmuka bertujuan untuk memberikan gambaran aplikasi kepada user.Perancangan antarmuka meliputi struktur menu, input dan output aplikasi, dan fungsi fungsi yang ada di dalam aplikasi (terlampir).

\section{Arsitektur Sistem}

Arsitektur sistem yang dibangun terdiri dari 3 komponen yaitu:

\section{MobileDevice}

Perangkat yang menjalankan aplikasi Android yang menggunakan C2DM.Ini harus perangkat Android yang memiliki Market yang sudah terinstal, dan harus memiliki minimal satu login akun Google.

\section{ApplicationServer}

Server aplikasi yang sudah pengembang tetapkan sebagai bagian dari pelaksanaan C2DM dalam aplikasi mereka.Server aplikasi pihak ketiga mengirim data ke aplikasi Android pada perangkat melalui server C2DM. 


\section{C2DMServer}

Server Google yang terlibat dalam mengambil pesan dari server aplikasi pihak ketiga dan mengirim ke perangkat mobile.

\subsection{Implementasi}

Tahap ini akan menerjemahkan design yang telah dibuat pada point 2 ke dalam bahasa pemrograman. Bahasa pemrograman yang digunakan untuk membangun aplikasi inti adalah Java dan PHP FrameworkCodeIgniter, sedangkan databasenya menggunakan MySQL.

\subsection{Pengujian Sistem}

Pengujian sistem yang dilakukan adalah menggunakan BlackBoxTest atau disebut juga uji fungsional, yaitu menguji yang mengabaikan mekanisme internal sistem atau komponen dan hanya berfokus pada output dihasilkan dalam menanggapi input yang dipilih dan kondisi eksekusi [13].

Pengujian aplikasi ini dilakukan oleh Programmer untuk memberikan penilaian atau tanggapan apakah program yang dihasilkan telah dapat berjalan baik dan sesuai kebutuhan.

\section{HASIL DAN PEMBAHASAN}

\subsection{Hasil Pengumpumpulan Data}

Berdasarkan hasil pengumpulan data yang telah dilakukan di UMKM Bos Jangkrik Jogja. Diperoleh data-data yang bias dijadikan untuk mendukung penelitian. Data-data tersebut diantaranya adalah sebagai berikut:

\section{Data Hasil Wawancara}

Dari hasil wawancara dengan Pimpinan UMKM Bos Jangkrik Jogja Ahmad Nur Shoim S.E diperoleh informasi tentang proses bisnis berternak Jangkrik yaitu sebagai berikut :

A. Peternak mendaftar sebagai anggota UMKM Bos Jangkrik Jogja di Kantor
Pemasaran UMKM Bos Jangkrik Jogja

B. Petugas mencatat data peternak

C. Peternak membeli bibit (Telur Jangkrik) di Kantor Pemasaran UMKM Bos Jangkrik Jogja

D. Petugas mencatat jumlah bibit (Telur jangkrik) yang dibeli oleh Peternak

E. Petugas memberitahu cara menetaskan bibit (telur Jangkrik) dan memberi Informasi mengenai tanggal penetasannya.

F. Apabila telur sudah menetas, pada hari ke-1 Petugas dating ke lokasi peternakan untuk memberi informasi mengenai pakan jangkrik di Usia 1-10 Hari (Starter)

G. Pada hari ke-11 petugas dating kelokasi peternakan untuk memberi informasi mengenai pakan jangkrik di Usia 11-20 Hari (Grower)

H. Pada hari ke-21 petugas dating kelokasi peternakan untuk memberi informasi mengenai pakan jangkrik di Usia 21-28 Hari (Finisher)

I. Pada hari ke-28, Petugas memberi informasi mengenai Usia panen jangkrik melalui SMS.

J. Peternak melakukan pemanenan Jangkrik dan menyetor Hasil panen ke Kantor Pemasaran UMKM Bos Jangkrik Jogja

K. Petugas mencatat hasil panen berupa Jumlah Hasil Panen (Kg) dan Jumlah Nominal pembelian Jangkrik dari peternak.

L. Petugas memberikan Nota pembelian hasil Panen kepada Peternak.

M. Setelah transaksi pembelian Hasil Panen Jangkrik dilakukan, peternak dapat meninggalkan Kantor Pemasaran UMKM Bos Jangkrik Jogja

\section{Data Hasil Observasi}

Dari hasil observasi yang telah dilakukan di UMKM Bos Jangkrik Jogja 
diperoleh data tentang penetasan, takaran pakan, dan jenis pakan yang diberikan selama proses ternak berlangsung yaitu:

A. Telur Jangkrik akan menetas 5 hari setelah peternak mengambil telur.

B. Takaran dan Jenis Pakan jangkrik pada hari ke 1-10 Hari (Starter) adalah Sawi Putih, Gambas, Kedelai Halus, dan Voer Halus $1 \mathrm{Kg}$.

C. Takaran dan Jenis Pakan jangkrik pada hari ke 11-20 Hari (Grower) adalah Sawi Putih, Gambas, Sidogori, Wortel, Labu Siam, Bayam, Kacang Panjang, dan Voer Halus $3 \mathrm{Kg}$.

D. Takaran dan Jenis Pakan jangkrik pada hari ke 21-28 Hari (Finisher) adalah Ubi, Singkong, Jagung halus, Buncis, Sidogori, Kol, Daun Singkong, dan Voer Halus $5 \mathrm{Kg}$.

E. Pada Usia 28 Hari jangkrik sudah memasuki masa panen, karena jika usia lebih dari 28 hari akan tumbuh bulu sehingga Jangkrik tidak laku dipasaran.

\subsection{Analisis Kebutuhan}

Pada tahap ini dilakukan analisis system berdasarkan hasil pengumpulan data yang dilakukan untuk membangun Aplikasi Mobile Pendampingan Ternak jangkrik Menggunakan Metode Android to Device Messaging (AC2DM).Analisis kebutuhan sistem yang dilakukan mencakup kebutuhan user dan kebutuhan sistem.

\section{Kebutuhan User}

Kebutuhan user yang terkait dalam Aplikasi Mobile Pendampingan Ternak jangkrik Menggunakan Metode Android to Device Messaging (AC2DM) terdiri dari kebutuhan Peternak dan Petugas Pendamping Ternak.

a. Peternak

1) Peternak dapat Login pada Aplikasi di perangkat Mobile

2) Peternak dapat menerima informasi jadwal kegiatan dalam proses ternak
3) Peternak dapat melihat history dari informasi mengenai jadwal kegiatan dalam proses ternak

b. Petugas Pendamping Ternak

1) Petugas Pendamping Ternak dapat Login ke Aplikasi Web.

2) Petugas Pendamping Ternak dapat melayani registrasi Peternak.

3) Petugas Pendamping Ternak dapat melayani penjualan bibit

4) Petugas Pendamping Ternak dapat melayani pembelian hasil panen

5) Petugas Pendamping Ternak dapat mengelola harga jual dan beli

6) Petugas Pendamping Ternak dapat Logout dari Aplikasi Web.

2. Kebutuhan Sistem

Analisis sistem yang dilakukan mencakup kebutuhan terkait fungsional, kebutuhan terkait non-fungsional dan use case.

a. Kebutuhan Fungsional

1) Masuk sistem $\mathrm{Web}$

Sistem akan mengijinkan Petugas Pendamping Ternak untuk masuk ke sistem jika username dan password yang diinputkan benar.

2) Mengolah Data Peternak

Sistem akan menyediakan form input data peternak dan akan menyimpan data yang diinput dan diolah oleh Petugas Pendamping Ternak

3) Mengolah Data Penetasan

Sistem akan menyediakan forminput data penetasan telur dan akan menyimpan data yang diinput dan diolah oleh Petugas Pendamping Ternak

4) Mengolah Data Pembelian Hasil Panen

Sistem akan menyediakan forminput data pembelian hasil panen dan akan menyimpan data yang diinput dan diolah oleh Petugas Pendamping Ternak 
5) Keluar Sistem $\mathrm{Web}$

Sistem akan mengijinkan Petugas Pendamping Ternak untuk keluar dari sistem.

6) Masuk ke Sistem Aplikasi Mobile

Sistem akan mengijinkan User untuk masuk ke system jika username dan password yang diinputkan benar.

7) Notifikasi jadwal kegiatan ternak

Sistem akan menampilkan notifikasi jadwal kegiatan ternak berupa suara dan text pada Aplikasi Mobile.

\section{8) NotificationHistory}

Sistem akan menampilkan menu NotificationHistory pada Perangkat Mobile apabila Notifikasi yang muncul belum dibaca oleh User.

9) Keluar dari system Aplikasi Mobile

Sistem akan mengijinkan User untuk keluar dari sistem.

b. Kebutuhan Non Fungsional

1. Operational

Aplikasi Mobile Pendampingan Ternak jangkrik Menggunakan Metode Android to DeviceMessaging (AC2DM) membutuhkan koneksi internet agar bias berjalan.Ukuran aplikasi Aplikasi adalah 4 MB dan kecepatan penyimpanan datanya kurang lebih 1 menit. Tampilan notifikasi jadwal kegiatan ternak adalah menggunakan model PushNotifications.

\section{Security}

A. Semua password dilindungi secara enkripsi

B. Hanya User yang sudah terdaftar yang dapat menggunakan Aplikasi Mobile pendampingan ternak.

\section{c. UseCase}

Usecase diagram digunakan untuk menggambarkan proses yang dapat dilakukan oleh user. Pembuatan use case ini didasarkan pada analisis kebutuhan fungsional Aplikasi Mobile
Pendampingan Ternak jangkrik Menggunakan Metode Android to Device Messaging (AC2DM).

Gambar 1 merupakan Use Case Diagram pada Aplikasi Mobile Pendampingan Ternak jangkrik Menggunakan Metode Android to Device Messaging (AC2DM).Terdapat 2 klasifikasi user, yaitu Peternak dan Petugas Pendamping Ternak.

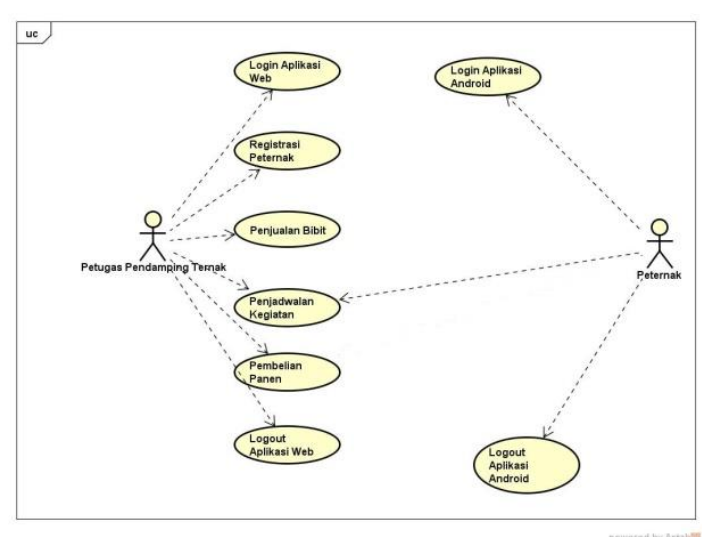

Gambar 1.UseCase Diagram

\subsection{Perancangan Sistem}

Perancangan sistem merupakan tahap selanjutnya setelah analisis sistem. Perancangan sistem digunakan untuk mendapatkan gambaran tentang apa yang dikerjakan pada analisis sistem untuk membentuk sistem tersebut. Berikut ini adalah perancangan sistem Aplikasi Mobile Pendampingan Ternak jangkrik Menggunakan Metode AndroidtoDeviceMessaging(AC2DM).

\section{A. ActivityDiagram}

Activity Diagram digunakan untuk menggambarkan proses bisnis dan urutan aktivitas dalam sebuah proses. Berikut ini activity diagram yang ada pada sistem Aplikasi Mobile Pendampingan Ternak Jangkrik Menggunakan Metode Android Cloud to Device Mesaging (AC2DM).

\section{B. Entity Relational Diagram}

Entity Relational Diagram (ERD) digunakan untuk memodelkan struktur data dan hubungan antar data.ERD juga digunakan untuk merancang basis data pada aplikasi web pendampingan ternak jangkrik. 


\section{Maping Table}

Setelah merancang model basis data dengan ERD tahap selanjutnya adalah memetakan entitas atau relasinya kedalam sebuah tabel. Mapping table mempunyai ketentuan yaitu setiap entitas pasti berubah menjadi tabel serta atributnya akan menjadi field dari tabel tersebut. Sedangkan relasi bisa berubah menjadi tabel dan bisa juga tidak. Berdasarkan ERD yang telah dibuat, kardinalitas yang dihasilkan dari semua relasi yang ada adalah $1-\mathrm{N}$ (one to many) sehingga relasi tidak menjadi tabel, melainkan dilakukan penambahan primary key dari entitas dengan kardinalitas 1 ke entitas dengan kardinalitas $\mathrm{N}$.

\subsection{Implementasi}

Aplikasi Android Manajemen Ternak Jangkrik di UMKM Bos Jangkrik Jogja terdiri dari dua sistem, yaitu sistem web untuk Petugas Pendamping Ternak yang dibuat menggunakan framework PHP CodeIgniter dan sistem pada Aplikasi Mobile yang dibuat menggunakan Pemrograman Android.

\subsubsection{Aplikasi Web}

Aplikasi Web memiliki sistem Dashboard seperti yang digambarkan pada Gambar 3 . Pada gambar 3 memberikan fungsi untuk administrasi sistem seperti pengolahan data peternak, bibit, hasil panen, harga, dan penjadwalan.

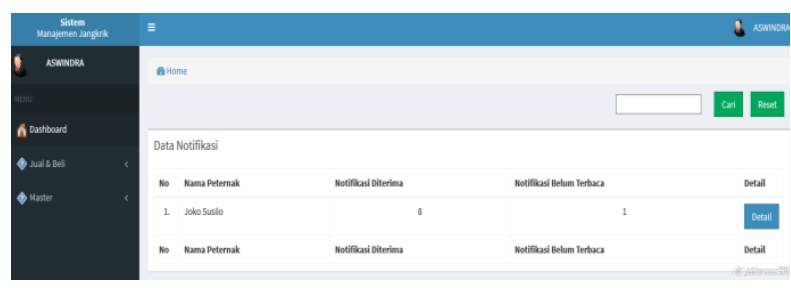

Gambar 3. Halaman Web

\subsubsection{Aplikasi Mobile}

Gambar 4 merupakan tampilan PushNotification jadwal kegiatan ternak pada Aplikasi Mobile.

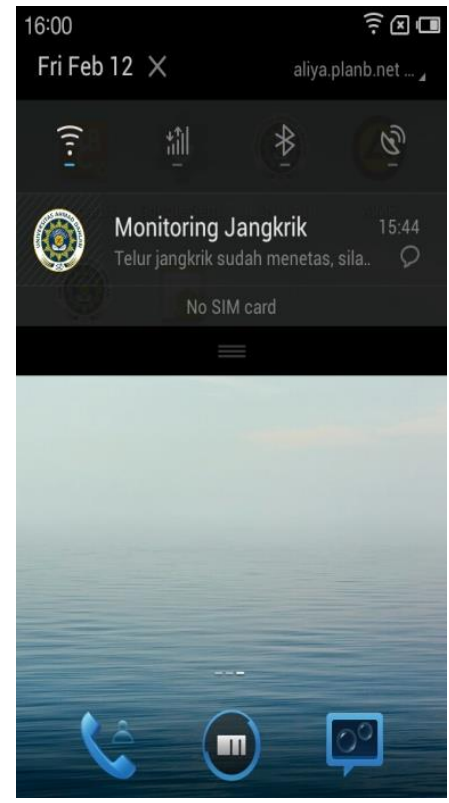

Gambar 4. Tampilan Push Notification

Gambar 5 merupakan tampilan dari detail notifikasi. Pada saat pengguna masuk ke dashboard dan memilih tanggal pembelian, maka sistem akan menampilkan history notifikasi yang sudah masuk ke perangkat mobile. Kemudian apabila pengguna memilih list dari history notifikasi maka akan muncul detail notifikasi berupa AlertDialog.

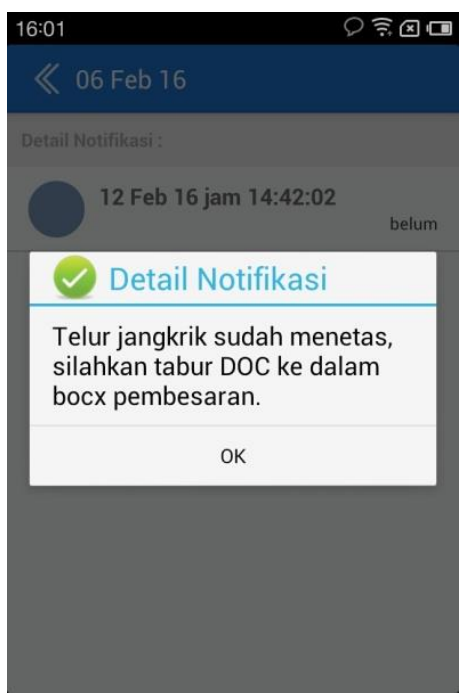

Gambar 5. Tampilan Detail Notifikasi

Gambar 6 merupakan tampilan dari Cron Job. Cron Job merupakan suatu tools yang digunakan untuk mengatur tugas secara terjadwal dalam melakukan pengiriman notifikasi dan melakukan konfigurasi jangka waktu periodek untuk mengeksekusi suatu file. 


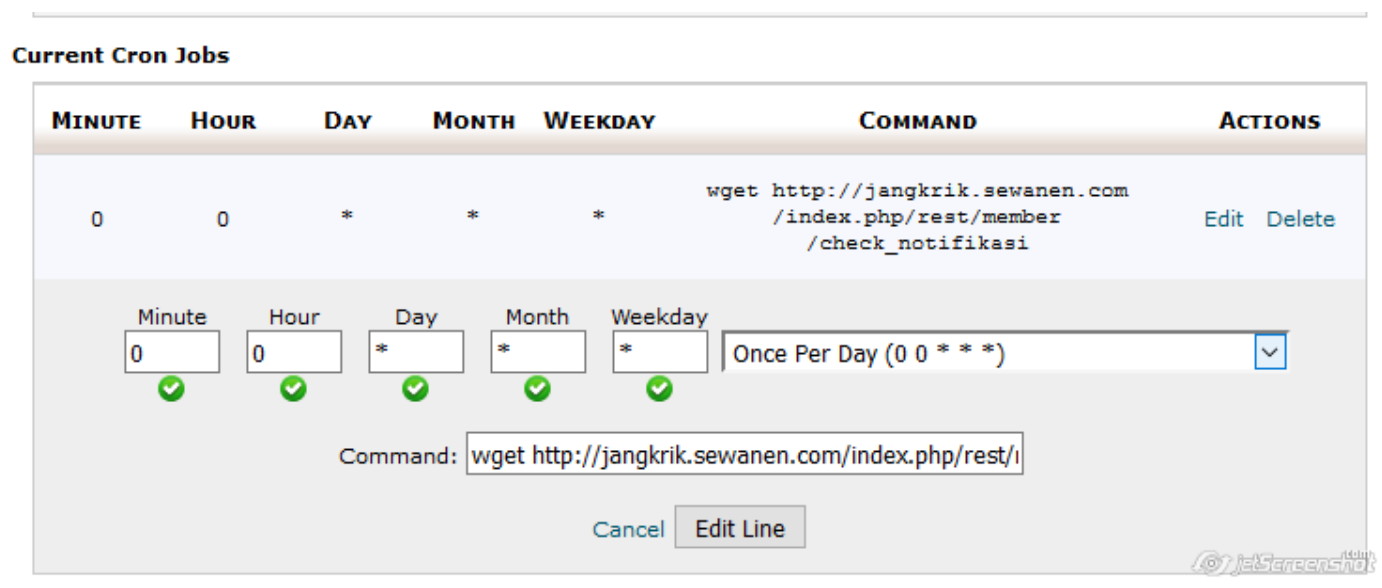

Gambar 6. Tampilan Cron Job

\subsection{Pengujian Sistem}

Pengujian sistem merupakan tahap akhir dari proses pembangunan sistem ini. Metode yang digunakan untuk pengujian sistem Aplikasi Mobile Pandampingan Ternak Jangkrik menggunakan blackboxtest. Pengujian BlackBox dilakukan untuk menguji antarmuka aplikasi, menyediakan input dan memeriksa outputnya untuk menguji fungsi yang ada di aplikasi sudah berjalan dengan benar.

Pengujian ini dilakukan oleh user dengan berinteraksi langsung dengan aplikasi dalam bentuk tertulis. Pengujian dilakukan oleh programmer dari "Plan B Network" yaitu Wisnu Arisandy. Pengujian dilakukan dengan memberikan lembar isian kepada tester, kemudian tester melakukan pengujian dan menuliskan hasil keluarannya kedalam lembar yang telah diberikan.

\section{KESIMPULAN DAN SARAN}

\subsection{Kesimpulan}

Berdasarkan hasil penelitian yang telah dilakukan pada Aplikasi WebMobile Manajemen Ternak Jangkrik dapat disimpulkan bahwa :

1. Telah dibangun Aplikasi Web untuk Petugas Pendamping Ternak sehingga Petugas Pendampingan Ternak dapat memanajemen kegiatan ternak melalui
Komputer, tidak datang langsung ke lokasi peternak.

2. Telah dibangun System yang mampu mengirim Notifikasi jadwal proses kegiatan ternak secara otomatis dan mampu menerima feedback dari peternak mengenai pelaksanaan jadwal proses kegiatan ternak sehingga proses penyampaian dan penerimaan informasi jadwal proses kegiatan ternak dapat dilakukan kapanpun dan dimanapun.

\subsection{Saran}

Pengembangan Aplikasi Mobile pada penelitian ini masih memiliki keterbatasan, maka diharapkan adanya pengembangan dimasa mendatang. Berikut beberapa saran yang dikemukakan terkait dengan penelitian pada Aplikasi Mobile ini adalah :

1. Diharapkan adanya pengembangan sistem dengan menambah fitur Grafik perkembangan hasil panen agar peternak dapat melihat secara detail mengenai perkembangan ternak mereka.

2. Program aplikasi ini dapat dikembangkan lagi dengan menambah fitur laporan keuangan untuk merekap data Jual dan Beli agar Petugas Pendamping Ternak lebih mudah dalam membuat laporan keuangan. 


\section{DAFTAR PUSTAKA}

[1] Ahmad, M. (2014). Data Statistik Internet Indonesia 2014. Yogyakarta: Andi.

[2] Paimin, B. (1999). Sukses Berternak Jangkrik. Jakarta Pusat: Niaga Swadaya.

[3] Gargenta, M. (2011). Learning Android. USA: O'Reilly Media.

[4] Google. (2012, September 26). Android Cloud to Device Messaging Framework Android Google Developers. Retrieved Januari 6, 2015, from Android Google Developers:

https://developers.google.com/android/c2 $\mathrm{dm} /$

[5] Paranginangin, K. (2006). Aplikasi Web Dengan PHP Dan MySQL. Yogyakarta: Andi.

[6] Potts, S. (2003). Sams Tech Yourself Web Service In 24 Hours. USA: SAMS Publishing.

[7] Prayogi, G. (2014, Januari 21). Pengguna Smartphone Tembus 1,25 Miliar di 2014. Retrieved Oktober 31, 2014, from Okezone Techno: http://techno.okezone.com/read/2014/01/ 20/57/928972/pengguna-smartphonetembus-1-25-miliar-di-2014

[8] Sidik, B. (2012). Pemrograman Web Dengan PHP. Bandung: Informatika.

[9] Sidik, B., 2012. Framework Codeigniter, Bandung: Informatika.

[10] Soenarto, H. (1999). Berternak Jangkrik. Solo: Pabelan Cerdas Nusantara.

[11] Sommerville, I., 2007. Software Engineering 8th ed., Pearson Education Limited.

[12] Suarga. (2009). Dasar Pemrograman Komputer Dalam Bahasa Java. Yogyakarta: Andi.

[13] Williams, L., 2011. A (Partial) Introduction to Software Engineering Practices and Methods., 2011. Available at:

https://online.ist.psu.edu/sites/ist412/files/ williamstext.pdf 